\title{
Adenovirus-mediated RNA interference against herpes simplex virus infection in vitro
}

\author{
Lin Chen, Zhi-Qiang Pan, Chang-Bin Zhai
}

Ophthalmic Center, Beijing Tongren Hospital, Capital Medical University, Beijing Ophthalmology, and Visual Sciences Key Lab, Beijing 100730, China

\begin{abstract}
Introduction. Herpetic keratitis caused by the herpes simplex virus (HSV) is the most common form of ocular herpes that causes corneal blindness. Although treatments for herpes keratitis have improved in recent years. there is still considerable room for new treatments against viral infection that shows great promise. The aim of the study was to evaluate the effect of RNA interference on HSV Type 1 (HSV1) infection in vitro, first prophylactically then therapeutically.

Material and methods. The highly conserved glycoproteins $\mathrm{D}(\mathrm{gD})$ and $\mathrm{E}(\mathrm{gE})$ were chosen as targets for this study. Different small interfering RNA (siRNA) duplexes that target $\mathrm{gD}$ and $\mathrm{gE}$ were designed and chemically synthesized. The recombinant adenovirus type 5 was developed and used as the vehicle with which we delivered the siRNA into the Vero cells infected with the HSV1 KOS strain. Evaluation of the efficacy of siRNA-mediated inhibition was performed either before virus inoculation (prophylactically) or after virus inoculation at the first appearance of lesions (therapeutically). The expression of messenger RNA encoding gD and gE was detected using a real-time polymerase chain reaction (qPCR). We analyzed HSV replication in Vero cells, cytotoxicity of HSV, and cell viability.

Results. When used prophylactically, the siRNA-targeting $\mathrm{gD}$ and $\mathrm{gE}$ created a more marked decrease in viral titer than when used therapeutically. The transfection of cells with recombinant adenovirus containing the siRNA expression cassette was associated with very low cytotoxicity.

Conclusions. Adenovirus-mediated siRNA-targeting $\mathrm{gD}$ and $\mathrm{gE}$ genes effectively inhibit the replication of the HSV in Vero cells. In addition, these findings indicate that the prophylactic use of siRNA is far more effective at inhibiting HSV replication than the therapeutic use. (Folia Histochemica et Cytobiologica 2021, Vol. 59, No. 4, 302-310)
\end{abstract}

Key words: herpetic keratitis; HSV infection; Vero cells; glycoprotein D; glycoprotein E; adenovirus RNA interference; recombinant adenovirus type 5; cell viability

\section{Introduction}

The herpes simplex virus (HSV) often attacks the ocular and accessory structures [1]. Herpetic keratitis is a common form of ocular herpes and remains the

Correspondence address: Chang-Bin Zhai, MD

Ophthalmic Center, Beijing Tongren Hospital,

Capital Medical University, Beijing Ophthalmology,

and Visual Sciences Key Lab, No. 1 of Dongiiaominxiang,

Dongcheng District, Beijing 100730, China

phone: +8610601089269

e-mail: zhai148_15@126.com most common viral cause of corneal blindness [2]. Following primary ocular herpetic infection, the virus enters a latent phase. Recurrent immune keratitis or infections cause structural damage to the cornea and scarring, which may lead to blindness [3]. Despite concentrated research relating to herpes simplex virus keratitis (HSK), the medical treatment of this disease continues to be challenging [4]. A classic antiviral drug, a thymidine analog, has been shown to be effective. However, the long-term use of thymidine analogs can lead to a series of ocular abnormalities, including a punctate defect of the corneal epithelium and corneal ulcers [5]. Therefore, it is necessary to 
find a safer effective method for the treatment and prevention of herpetic keratitis [6].

HSV type 1 (HSV1) contains a genome of approximately $152 \mathrm{~kb}$ and is a large, double-stranded DNA (dsDNA) virus [7]. It is composed of an electron-opaque core, a capsid, a tegument, and an envelope [8]. The outermost envelope is composed of a lipid bilayer and approximately 12 embedded glycoproteins (gs). According to their various functions, these proteins can be divided into attachment proteins $(\mathrm{gB}, \mathrm{gC}$, $\mathrm{gD}, \mathrm{gH})$, immune escape proteins ( $\mathrm{gC}, \mathrm{gE}$, and $\mathrm{gI})$, fusion proteins $(\mathrm{gB})$, and structural proteins [9].

RNA-mediated interference (RNAi) is a phenomenon that inhibits gene expression in normal organisms and exists widely in many species [10]. RNAi enables dsDNA to silence the expression of specific genes [11]. In this process, dsDNA (exogenous or endogenous) is first degraded to a small-molecule double-stranded RNA, known as small interfering RNA (siRNA). After its formation, siRNA is associated with a number of specific proteins to form siRNA-induced interference complexes [12]. In these complexes, the antisense strand is used for sequence recognition by matching RNA sequences and directly cleaving to target messenger RNAs (mRNAs), which leads to specific gene silencing. The length of the mRNA (21-23 nucleotides) is short enough to ensure its specificity and avoid nonspecific mRNAs being destroyed. During this process, new siRNAs are produced, and the silencing effect may be amplified by several silencing cycles [13].

In this study, synthetic siRNA was used, mediated by recombinant human adenovirus type 5 (rAd5), to act directly against the HSV glycoproteins, $\mathrm{gD}$ and $\mathrm{gE}$, which was found to effectively inhibit HSV replication in cultured Vero cells.

\section{Materials and methods}

Cells and viruses. RAd5 was produced and grown by human embryonic kidney 293 cells (cell bank of the Chinese Academy of Sciences, Shanghai, China), and the virus titer was determined. HSV was cultured using African green monkey kidney (Vero) cells (ATCC, Manassas, VA, USA), and the virus infectivity was determined. The antiviral activity of the recombinant human adenovirus type 5-expressing short hairpin RNA (shRNA) was assayed in the Vero cells. All cells were cultured using Dulbecco's modified Eagle's medium (DMEM) containing 10\% fetal bovine serum (FBS; $\mathrm{pH}=$ 7.4) and incubated at $37^{\circ} \mathrm{C}$ with $5 \% \mathrm{CO}_{2}$. The HSV1 KOS strain (The Beijing Institute of Ophthalmology, Beijing, China) was used for the experiments. The virus was cultured in monolayers of Vero cells, titrated, and stored in equal amounts at $-80^{\circ} \mathrm{C}$ until used.
Selection of siRNA/shRNA targets and plasmid construction. Two HSV1 KOS strain glycoproteins, gD and gE, were selected as the siRNA targets. GenScript (https://www.genscript.com/, Piscataway, NJ, USA) was used to select the siRNA fragments. The specificity of the siRNA was examined using the NCBI BLAST database. Two siRNAs targeting gD (siRNA2 and siRNA3) and one targeting gE (siRNA4) were generated, as previously described [14]. The negative control (siRNA6) was designed using the Rosetta siRNA Design Algorithm. The following siRNAs (duplexes of sense and anti-sense strands) were synthesized using GenScript: siRNA1 (the blank PRNAT-H1.1/Shuttle plasmid), siRNA2 (5'-GGATCCCGTCTTTGCCGCGAAAGCGATTGTTGATATCCGCAATCGCTTTCGCGGCAAAGAT TTTTTCCAA-3'), siRNA3 (5'-GGATCCCGTAATCTCCGTCCAGTCGTTTATTGATATCCGTAAACGACTGGACGGAGATTATTTTTTCCAAAAGCTT-3', siRNA4 (5'-GGATCCCGTACAGACACGATTCGTATATTTTGATAT TCG AATATACGAATCGTGTCTGTATTTTTTCCAAAAGCTT-3'), and siRNA6 (5'-GGATCCCGTTCTCCGAACGTGTCACGTTTGATATCCGACGTGACACGTTCGGAGAATTTTTTCCAAAAGCTT-3'.

We used the siRNA expression vector pRNAT-H1.1/ /Shuttle (GenScript Corp., Piscataway, NJ, USA) to obtain a recombinant adenovirus shuttle vector that carries a green fluorescent protein (GFP) marker (Coral GFP). H1 was used as a promoter for the siRNA expression. The siRNA sequence was cloned into the pRNAT-H1.1 vector at its BamHI and HindIII sites. In brief, the complementary oligonucleotide single-stranded powder $(3 \mu \mathrm{g})$ was diluted in $30 \mu \mathrm{L} \mathrm{TE} \mathrm{solution} \mathrm{to}$ a final concentration of $1 \mu \mathrm{g} / \mu \mathrm{L}$. The reaction solution $(20 \mu \mathrm{L})$ including $1 \mu \mathrm{L}$ of top-strand oligo, $1 \mu \mathrm{L}$ of bottom-strand oligo, $1 \mu \mathrm{L}$ of $20 \times$ SSC (cat no. S6639, SigmaAldrich, St. Louis, MO, USA), and $17 \mu \mathrm{L}$ sterile purified water was prepared. After $10 \mathrm{~min}$ incubation at $95^{\circ} \mathrm{C}$, the reaction solution was diluted to a concentration of $40 \mathrm{ng} / \mu \mathrm{L}$ at room temperature. Then, the pRNAT-H1.1 vector was treated with endonucleases BamHI (Takara) and HindIII (Takara, Otsu Shiga, Japan). The reaction system, including $1 \mu \mathrm{L}$ Hind III, $1 \mu \mathrm{L}$ BamH, $2 \mu \mathrm{L} 10 \times$ Kbuffer, $1 \mu \mathrm{L}$ pRNAT- H1.1 vector $(1 \mu \mathrm{g} / \mu \mathrm{L})$, and $16 \mu \mathrm{L}$ sterile purified water, was kept at $37^{\circ} \mathrm{C}$ for $2 \mathrm{~h}$. The vector was then purified and ligated with the insert using T4 ligase (the molar ratio of insert to vector is $3: 1$ ).

Production of the recombinant human adenovirus type 5 (rAd5) particles. Adeno-X Viral DNA was purchased from Clontech Laboratories, Inc. (Mountain View, CA, USA). After amplification in E. coli, the expression cassette was excised from the pRNAT-H1.1 at the I-CeuI and PI-SceI sites and ligated to Adeno-X Viral DNA (the adenoviral genome). The ligated products were digested using Swa I to reduce the frequency of formation of non-recombinant clones. The recombinant adenoviral plasmids were 
transformed into E. coli cells. Plasmids were extracted and screened using agarose gel electrophoresis and identified by double-digestion with selected PI-SceI and I-CeuIto positive clones. The resultant adenoviral plasmids were linearized using PacI and purified by ethanol precipitation. In the final stage, the $5 \mu \mathrm{g}$ recombinant Adeno-X vector was packaged into infectious adenovirus by transfecting HEK-293 cells in a $25 \mathrm{~cm}^{2}$ flask using $20 \mu \mathrm{L}$ Lipofectamine ${ }^{\mathrm{TM}}$ Transfection Reagent 2000 (Invitrogen, Waltham, MA, USA). Transfected cells were observed for the GFP expression. Recombinant adenovirus was harvested by lysing the transfected cells for five days. Virus yields of 107-108 PFU/mL were obtained and stored in a freezer at $-70^{\circ} \mathrm{C}$ before use.

Cell culture and virus replication. Vero cells were grown as a monolayer in DMEM containing $10 \%$ FBS in a $25 \mathrm{~cm}^{2}$ flask at $37^{\circ} \mathrm{C}$ in a $5 \% \mathrm{CO} 2$ and $95 \%$ humidity incubator. The HSV KOS strain was kindly provided by the Beijing Institute of Ophthalmology. The viruses were propagated into the Vero cells by infecting the Vero cells at a multiplicity of infection (MOI) of 10. At approximately three days post-infection, the virus was harvested, clarified by centrifugation, and stored at $-70^{\circ} \mathrm{C}$ until needed. According to the $50 \%$ tissue, culture infective doses (TCID50) protocol, a virus stock solution containing approximately $10^{6}-10^{7} \mathrm{TCID} 50 / \mathrm{ml}$ was created.

Viral transfection at a cellular level. To evaluate the ability of rAd5 to inhibit HSV infection, $0.3 \times 10^{4}$ Vero cells, a cell line susceptible to rAd5 infection but not allowed to replicate productively, were inoculated into each well of a 96-well plate. On the second day, monolayers ( $95 \%$ confluent) of Vero cells were added with rAd5 and $0.1 \mathrm{~mL}$ of DMEM without FBS at MOIs of 1, 5, and 10. After adsorption for 12 hours, 100 TCID $_{50}$ HSV per $0.1 \mathrm{~mL}$ was incubated on the Vero cells monolayer without removing the rAd5 suspension. Infection was continued without removing the HSV, and the GFP expression and cytopathic effects (CPE) were examined using a microscope. Images were collected using an Olympus fluorescence microscope and a Canon camera (magnification $40 \times$ ) at an exposure time of $1 \mathrm{~s}$. The infected cells were freeze-thawed three times and centrifuged at $13,000 \mathrm{rpm}$ for $15 \mathrm{~min}$ at $4^{\circ} \mathrm{C}$. The supernatants were harvested at various times after infection, and the virus titers were determined three times on the Vero cells.

\section{Gene Expression Analysis Using Real-Time Polymerase} Chain Reaction. To detect the specific gene expression, total RNA was extracted from the HSV cultures using the RNeasy Micro Kit (QIAGEN, Shanghai, China) to detect HSV replication. The cells were lysed in Buffer RLT, and RNA was extracted according to the manufacturer's instructions. To generate complementary DNA (cDNA), $0.5-1 \mu \mathrm{g}$ of total RNA was reverse transcribed using the Quantscript RT Kit (TIANGEN, Beijing, China) with Oligo (dT) 15 Primer. All
cDNA samples were aliquoted and stored at $-20^{\circ} \mathrm{C}$ until needed. Relative quantitative real-time polymerase chain reaction (RT-PCR) was performed using a CFX96 real-time system (Bio-Rad, Shanghai, China). PCR was performed using the iQ SYBR Green Supermix (Bio-Rad) according to the manufacturer's protocol.

In the optimization of primers, $1 \%$ agarose gel analysis confirmed the predicted size of the product without primer dimer bands. The melting curve also verified that each oligonucleotide group did not form a primer dimer. RT-PCR was performed in $0.2 \mathrm{~mL}$ PCR 8-tube strips (Bio-Rad) in $20 \mu \mathrm{L}$ reaction solution containing the components of the SYBR PCR kit (iQ SYBR Green Supermix, Bio-Rad). The concentration of each primer was $10 \mu \mathrm{M}(0.8 \mu \mathrm{L})$ and the volume of cDNA was $2 \mu \mathrm{L}$. The cycle program was $94^{\circ} \mathrm{C}$ for $2 \mathrm{~min}, 40$ cycles at $94^{\circ} \mathrm{C}$ for $30 \mathrm{sec}, 60.1^{\circ} \mathrm{C}$ for $15 \mathrm{sec}, 72^{\circ} \mathrm{C}$ for $30 \mathrm{sec}$, and a Melt Curve of $55-90^{\circ} \mathrm{C}$ with increments of $0.5^{\circ} \mathrm{C}$ for $2 \mathrm{sec}$. The genes of interest were retrieved from PubMed and the primers were designed using the IDT SciTools PrimerQuest software. The primers were synthesized by Sangon (Shanghai, China): human beta-actin sense: TGG CCG TAA GGG TGT TGA TGA AGT, beta-actin anti-sense: AGG ACA TCG AGA CAT CGC GTT CAT; gD sense: GCA AAT CCC ACC AAA CTG GCA CAT, gD anti-sense: ACA CAA TTC CGC AAA TGA CCA GGG; gE sense: TTC AGC ACG AAC GTC TC C ATC CAT, gE anti-sense: TCG TAT ATT CGC ATC TCG GCA CAC. Assays were performed in triplicate. All experiments included a non-template control to monitor the DNA contamination of the reagents used. RT-PCR was performed using the Bio-Rad CFX96 system and the fluorescence signal was detected in each cycle and recorded graphically using the CFX Manager Software.

Cytotoxicity assay. Cellular toxicity and proliferation were tested using the Cell Counting Kit-8 (CCK-8). The CCK8 is based on the MTT assay, which tests the activity of dehydrogenase in the mitochondria. The signal generated is directly proportional to cell proliferation and inversely proportional to cytotoxicity. Therefore, this method can detect cell activation.

For each experimental condition, cells were seeded at $3 \times 10^{4}$ in a volume of $100 \mu \mathrm{L}$ per well on a 96-well plate. All groups ( $\mathrm{n}=3$ in each), with or without siRNA and HSV, were incubated with CCK-8 reagent at $37^{\circ} \mathrm{C}$ for two hours. Well absorption was measured using a spectrophotometer (Multiskan Ex Primary Eia v. 2.1-0, Thermo Fisher Scientific, Waltham, MA, USA) at $450 \mathrm{~nm}$ with a reference wavelength of $650 \mathrm{~nm}$. All experiments were repeated three times, each performed in triplicate. The viability was expressed as percentages when compared with the non-treated control.

HSV titer. Titration was done using the end-point dilution assay. The supernatant fluids were harvested at various times 




A

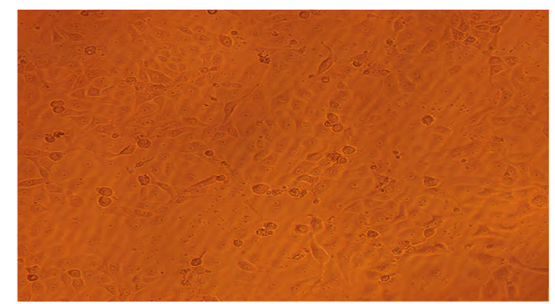

D

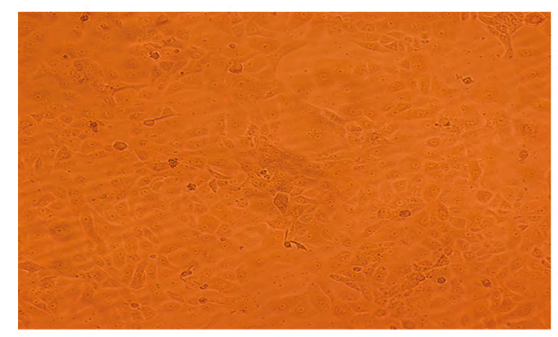

G

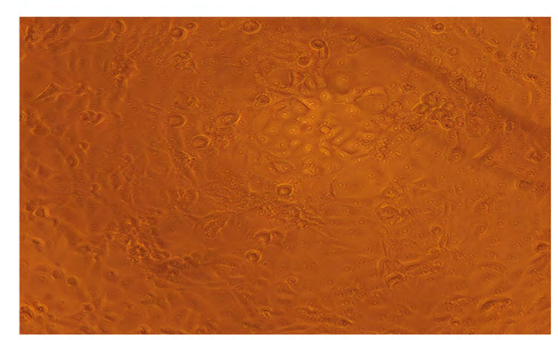

J



B

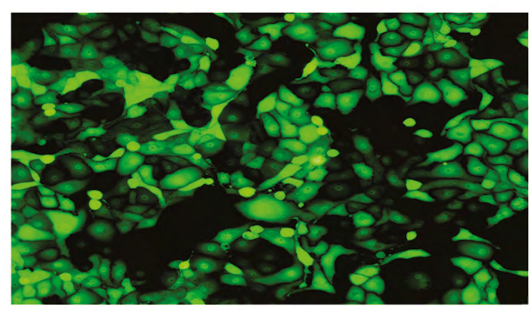

E

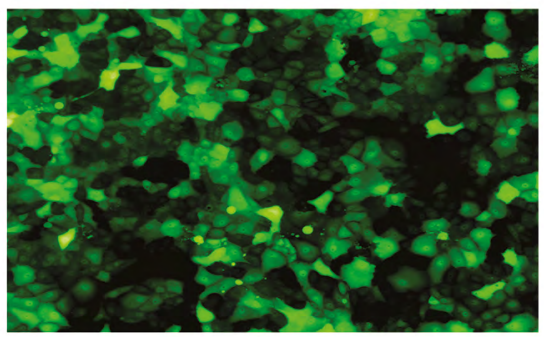

$\mathrm{H}$

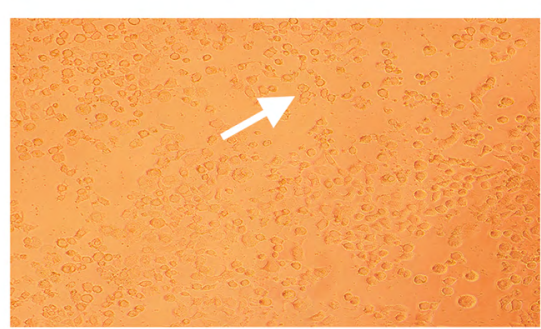

K

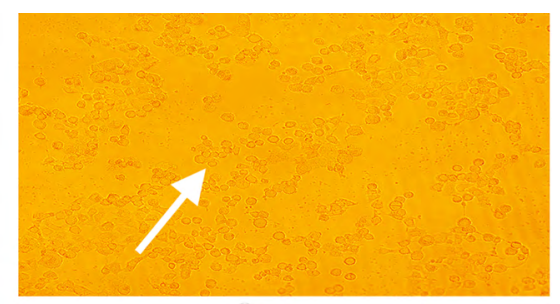

C

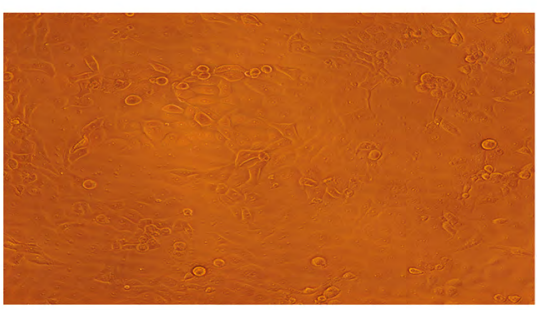

$\mathrm{F}$

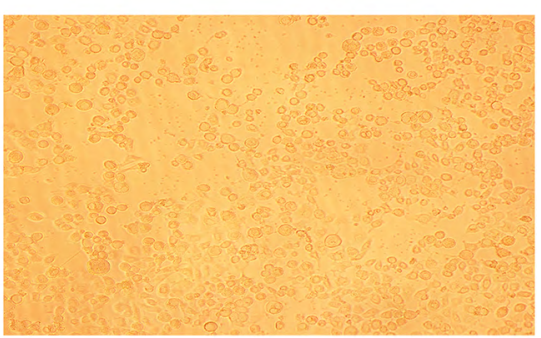

।

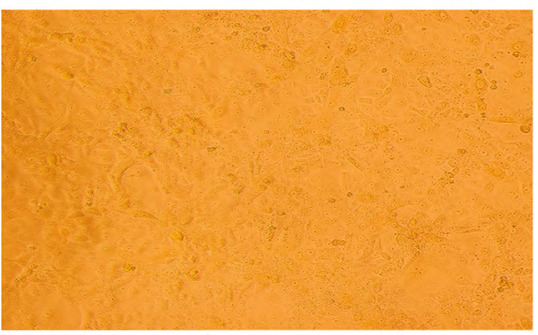

$\mathrm{L}$

$50 \mu \mathrm{m}$

Figure 1. Effect of rAd5-expressing herpes simplex virus (HSV)-specific siRNA on Vero cells. Light/fluorescence microscope photos of Vero cells transfected with siRNAs (12 h post-transfection) and infected with 100 TCID $_{50}$ of HSV (48 h post-infection). SiRNA1 (A, B, C), siRNA4 (D, E, F), siRNA6 (G, H, I). Positive control with $1 \mu \mathrm{m}$ of acyclovir (J). Negative control with $0.1 \mathrm{~mL}$ of DMEM $(\mathbf{K})$. Normal untreated Vero cells $(\mathbf{L})$. White arrows indicate that viral infection caused a marked cytopathy, shown as rounding, necrosis, and detachment of cells.

after infection and then frozen at $-80^{\circ} \mathrm{C}$ before titering and were titered three times on the Vero cells cultured in the 96-well plates.

Statistical analysis. All experiments were repeated at least two times. Data were analyzed using an unpaired two-tailed $t$-test, and a $p$-value $<0.05$ was considered to be statistically significant. All statistical analyses were performed using the SPSS software version 20 (IBM Corp., New York, NJ, USA).

\section{Results}

\section{The antiviral effect of rAd5-expressing} HSV-specific siRNA

Vero cells cultured in 96-well plates were inoculated with HSV-specific rAd5 at an MOI of 1, 5, or 10 to test the antiviral effect of siRNA. As controls, cells were treated with the same dose of blank rAd5 (siRNA1, Fig. 1A-C) or negative rAd5 (siRNA4, Fig. 1D-E; 


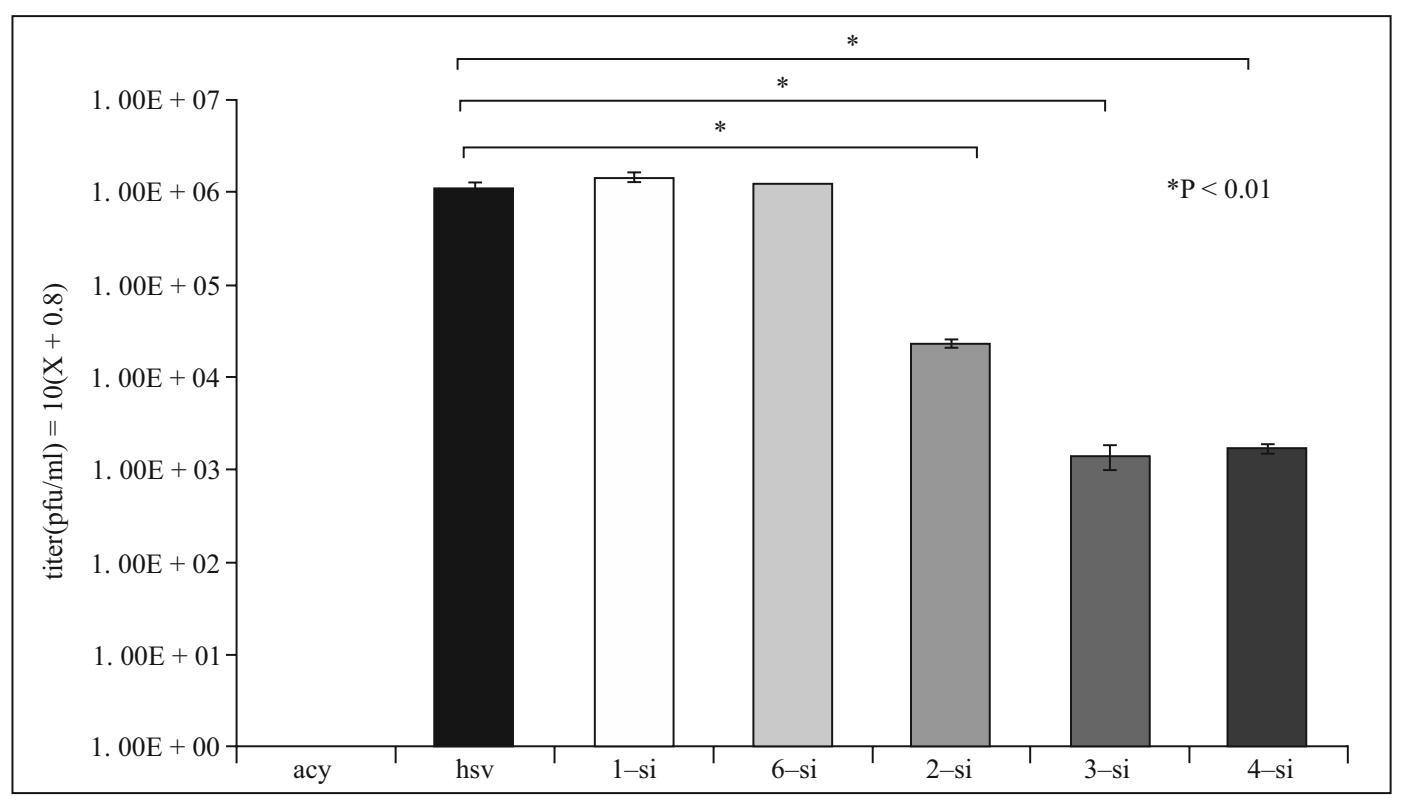

Figure 2. Effect of rAd5-expressing HSV-specific shRNA on virus yields. Vero cells were inoculated with shRNA-expressing rAd5 at an MOI of 10 and challenged $12 \mathrm{~h}$ post-inoculation with 100 TCID $_{50}$ of HSV KOS. Culture supernatants were collected $48 \mathrm{~h}$ after the HSV challenge, and virus yields were measured by TCID50 as described in Methods. The data are represented by mean \pm SD for the three separate experiments. Note: acy - acyclovir; hsv — herpes simplex virus; 1-si group, cells treated with siRNA1; 6-si group, cells treated with siRNA6; 2-si group, cells treated with siRNA2; 3-si group, cells treated with siRNA3; 4-si group, cells treated with siRNA4.

siRNA6, Fig. 1G-I) or were not treated. Acyclovir was used as a positive control (Fig. 1J), with a concentration of $1 \mu \mathrm{M}$. All cells were infected with 100 TCID50 for HSV after $12 \mathrm{~h}$. Normal Vero cells grow as monolayers and are fibroblastic in morphology (Fig. 1K, L). Viral infection causes a marked cytopathy, which is shown as a round up, necrosis, and detachment, as observed by microscopy (see Suppl. Fig. 1). Typical CPEs were seen in the cells of the control groups at $48 \mathrm{~h}$ but were not detected at any time in the cells treated with the HSV-specific siRNA at an MOI of 5 or 10. In the group treated with an MOI of 1, the CPEs developed after three days, suggesting that the antiviral effect was dose-dependent (see Fig. 1).

\section{Effect of rAd5-mediated RNAi on HSV replication}

The effect of rAd5-mediated RNAi on HSV replication was investigated by measuring the TCID50 of the supernatants of the cell lysates made at intervals post-challenge. In agreement with the microscopic observations, the supernatant TCID50 for HSV in the cells infected with siRNA2, 3, and 4 at an MOI of 10 was reduced (see Fig. 2). Virus formation was reduced $48 \mathrm{~h}$ after the challenge. Neither siRNA1 nor siRNA6 significantly inhibited the replication of HSV.

The toxicity of acyclovir was relatively low, and there were no significant differences between the
rAd5-treated group and the HSV group (see Fig. 3A). Cells were also inoculated with rAd5 at an MOI of 1, 5 , and 10 and challenged $24 \mathrm{~h}$ later with 100TCID of HSV. Figure 3B shows that there was no significant difference between the rAd5 at an MOI of 1 and the HSV group, but the cells were protected by the rAd5 at an MOI of 5 and 10. The analysis shows there was no significant difference between the rAd5 at an MOI of 5 and 10, and the rAd5 at an MOI of 10 exhibited increased cell survival.

\section{Effect of HSV-specific rAd5 on the levels of $g D$ and $g E$}

Cells treated with the rAd5 at an MOI of 10 and challenged with HSV were collected $24 \mathrm{~h}$ and $48 \mathrm{~h}$ post-challenge, and RT-PCR was performed to further substantiate the levels of inhibition. The levels of glycoproteins $\mathrm{gD}$ and $\mathrm{gE}$, as determined by RT-PCR, were significantly reduced in cells treated with the HSV-specific rAd5. These results indicate that the HSV-specific shRNA-expressing rAd5 can effectively and specifically inhibit infection by the virus in Vero cells (see Fig. 4). In all samples, siRNA inhibited the expression of the target gene. However, the silencing effects were not uniform and inhibition rates were higher at $48 \mathrm{~h}$ than at $24 \mathrm{~h}$, with the most effective inhibition observed in siRNA3. A combination of 


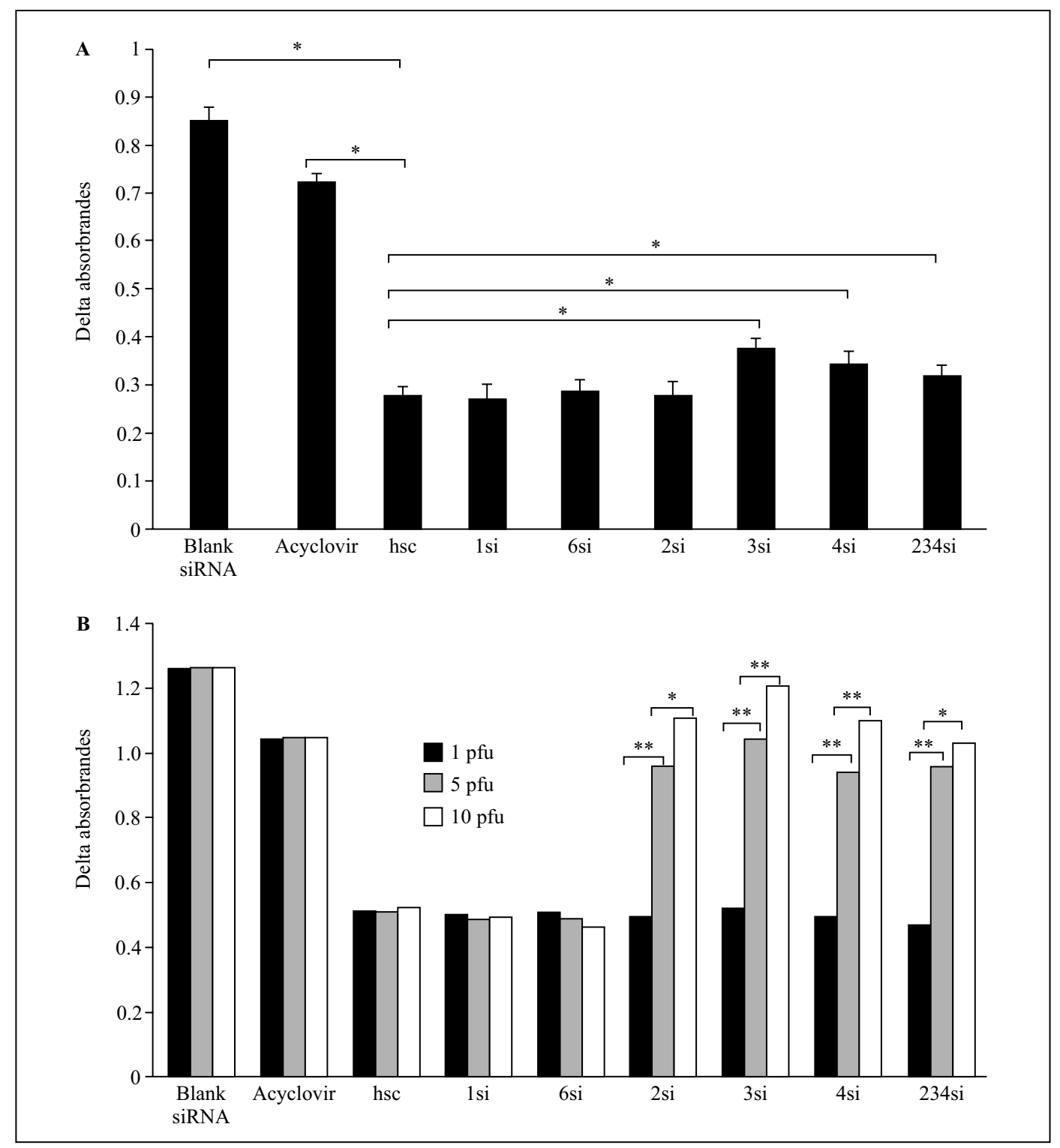

Figure 3. A. Vero cells were treated at an MOI of 10 with rAd5 and 100TCID HSV as described in Methods. 1, untreated cells; 2, cells treated with acyclovir + HSV; 3, cells treated with only HSV; 4, cells treated with siRNA1 (blank); 5, cells treated with siRNA6; 6 , cells treated with siRNA2; 7, cells treated with siRNA3; 8, cells treated with siRNA4; and 9, cells treated with siRNA2, 3, and 4. B. Cells were treated with 10 PFU rAd5 for $24 \mathrm{~h}$, and then HSV was added. Normal group, untreated cells; acyclovir group, cells treated with acyclovir + HSV; hsv group, cells treated with only HSV; 1si group, cells treated with siRNA1 (blank); 6si group, cells treated with siRNA6; 2si group, cells treated with siRNA2; 3si group, cells treated with siRNA3; 4si group, cells treated with siRNA4; 234si group, cells treated with siRNA2, 3, and 4.

siRNAs targeting different sites was more effective than a single siRNA.

\section{Discussion}

All studied herpes viruses share three common characteristics: first, the typical particle morphology; second, possession of a large genome consisting of a single molecule of dsDNA ranging between 120 and $250 \mathrm{kbp}$; and third, following productive infection, the ability to produce disease and enter a latent phase in some cells of the infected natural host [15]. In the virions, the genome is encapsulated within an icosahedral capsid displaying 162 morphological elements or capsomers. The capsid is, in turn, coated with a layer of proteins, called the tegument [16]. Several glycoproteins in the envelope are essential for viral entry into cells.

The viral envelope contains a dozen of viral glycoproteins, but only five $(\mathrm{gB}, \mathrm{gC}, \mathrm{gD}, \mathrm{gH}$, and $\mathrm{gL}$ ) have 


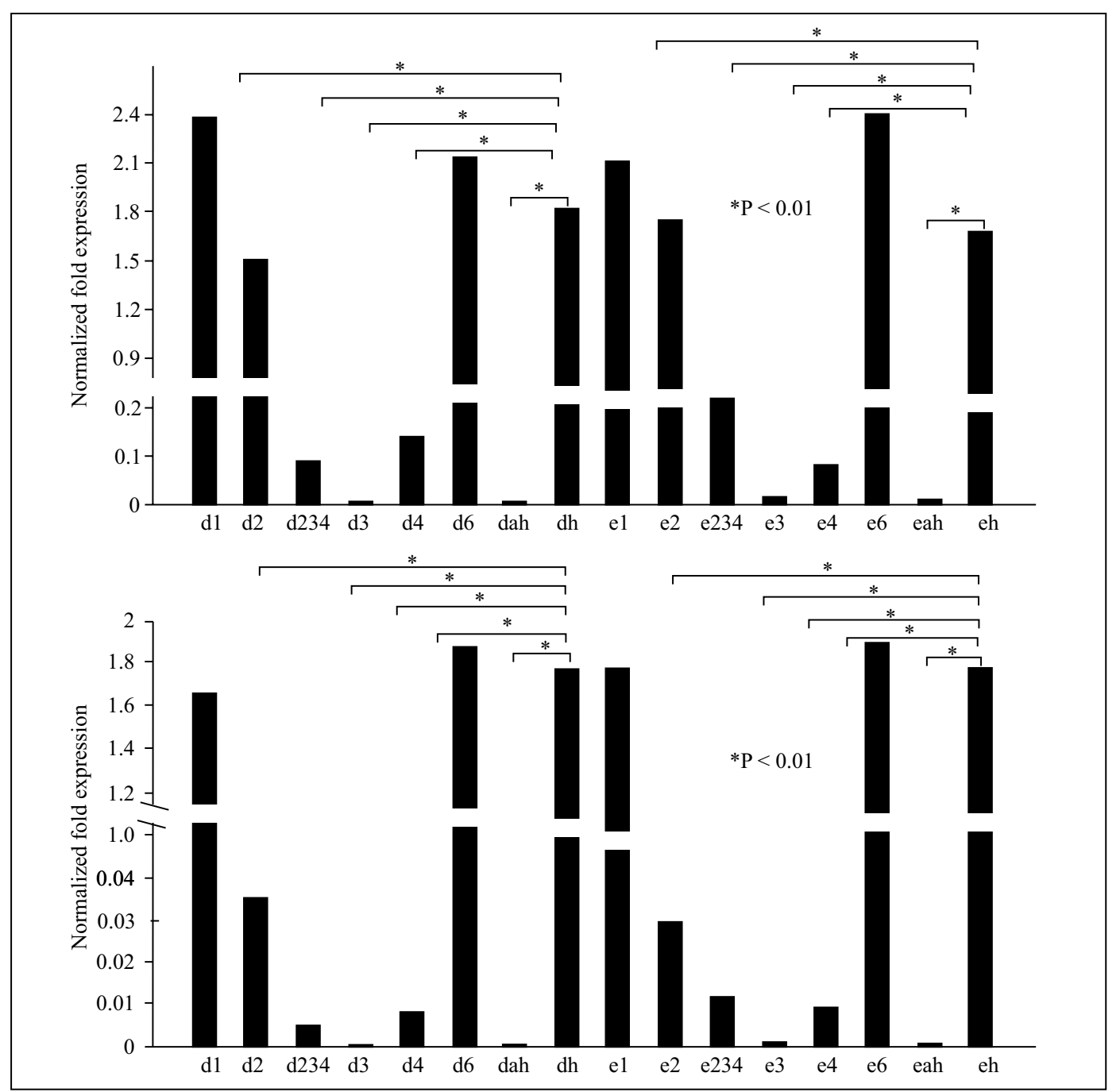

Figure 4. Cells treated with rAd5 at an MOI of 10 and challenged with HSV were collected $24 \mathrm{~h}$ and $48 \mathrm{~h}$ postchallenge. The levels of glycoproteins $\mathrm{gD}$ and $\mathrm{gE} \mathrm{mRNAs}$ were determined by RT-PCR. 1, cells treated with siRNA1 (blank); 2 , cells treated with siRNA2; 234, cells treated with siRNA2, 3, and 4; 3, cells treated with siRNA3; 4, cells treated with siRNA4; 6, cells treated with siRNA6; ah, cells treated with acyclovir + HSV; h, cells treated with only HSV; d, gD mRNA level; e, gE mRNA level. Graphs were obtained by using the CFX96 software.

been reported to participate in viral entry [17]. The HSV1 glycoproteins $\mathrm{gE}$ and gI form receptors for the Fc domain of immunoglobulin $\mathrm{G}(\mathrm{IgG})$ that are expressed on the surface of infected cells and the virion envelope and protect the virus from immune attack [18]. HSVs can initiate infection of cultured cells by adsorbing to the cell surface and then penetrating across the cell membrane [19]. The cell-to-cell spread of the HSV in the monolayers of certain cultured cells also involves the infection of adjacent cells across cell junctions [20]. Major participants in these processes include HSV glycoproteins that comprise the protein component of the virion envelope. HSV1 encodes at least 11 glycoproteins, of which $\mathrm{gB}, \mathrm{gD}, \mathrm{gH}, \mathrm{gK}$, and $\mathrm{gL}$ are essential for productive infections in cultured cells [21].
GE and gI act as receptors for the Fc domain of IgG. Previous evidence shows that $\mathrm{gE}$ - and gI-mutant viruses produce small dendritic lesions or microscopic punctures in the epithelium and no clinical symptoms of corneal disease or encephalitis [22]. Mutant viruses produce small plaques on monolayers of normal epithelial cells and human fibroblasts. However, the spread of gE- and gI-mutant viruses is significantly slower than wild-type HSV1. The gE-gI complex facilitates virus transfer across cell junctions [23].

HSV-1 is a major pathogen that can cause a variety of eye diseases and even blindness. Synthetic chemical drugs, such as acyclovir and ganciclovir, are the standard therapy for HSV-1 infection. However, the efficacy of these drugs is not satisfactory and the widespread use of them may lead to drug resist- 
ance $[24,25] . \mathrm{gD}$ and $\mathrm{gE}$ are essential for both virus entry and cell-to-cell spread during HSV infection [26-28]. Our results provide evidence that siRNAs corresponding to $\mathrm{HSV} \mathrm{gD}$ and $\mathrm{gE}$ gene sequence by adenovirus-mediated transfer is an effective method for the inhibition of virus replication and results in very low cytotoxicity. We also found that siRNAs were more effective prophylactically and that the RNA level in cells treated with a mixture of gD siRNA and gE siRNA was lower than that in cells treated with a single siRNA. These results indicated that to attain the highest levels of virus replication silencing, more than one siRNA targeted to different sites needs to be used.

The potent inhibitory effect of single siRNA on HSV-1 has been reported [29]. In an in vitro infection model, exogenous siRNA inhibited the expression and function of HSV-1 glycoprotein E during active infection [30]. However, due to the genetic variability of HSV-1 [31-33] and escape mutations in the targeted sequences [34-37], the application of a single siRNA is limited. Therefore, multiple siRNAs targeting conserved viral sequences need to be combined [38]. Jin et al. studied multiple HSV-1 capsid proteins by using designed and chemically synthesized siRNAs, and showed that siRNAs acting alone or in combination with another siRNA effectively inhibited the expressions of VP23 (UL18) and VP5 (ul19) genes, thereby inhibiting the replication of HSV-1 virus, with a more robust effect observed in combination [39]. The use of multiple siRNAs may also make it more difficult for the virus to evade the RNAi effect through a mutation in the target sequence.

Despite the rapid advances in the development of RNAi as novel therapeutic antivirals [40-42], there were few studies exploring the prophylactic potential for RNAi approaches to the virus. The present study showed that under in vitro conditions the prophylactic application of siRNAs resulted in a higher inhibition of virus replication in comparison with the therapeutic application. The mechanism might be the result of direct degradation of viral RNA by preexisting siRNA within cultured cells upon entry of the viral particle, blocking replication. The underlying mechanism warrants further investigations.

In summary, our study showed that siRNAs potently inhibited HSV-1 in cell lines. We suggest that the results have significant implications for the use of siRNA as a therapeutic method for the prophylaxis of HSV-1.

\section{Acknowledgments}

We would like to acknowledge the hard and dedicated work of all the staff that implemented the intervention and evaluation components of the study.

\section{Financing}

Beijing Science and Technology Nova Program(SKW-KJXX-2003-01).

\section{Competing interests}

The authors declare that they have no competing interests.

\section{References}

1. Giménez F, Suryawanshi A, Rouse BT. Pathogenesis of herpes stromal keratitis--a focus on corneal neovascularization. Prog Retin Eye Res. 2013; 33: 1-9, doi: 10.1016/j.preteyeres.2012.07.002, indexed in Pubmed: 22892644.

2. Austin A, Lietman T, Rose-Nussbaumer J. Update on the Management of Infectious Keratitis. Ophthalmology. 2017; 124(11): 1678-1689, doi: 10.1016/j.ophtha.2017.05.012, indexed in Pubmed: 28942073.

3. Azher TN, Yin XT, Tajfirouz D, et al. Herpes simplex keratitis: challenges in diagnosis and clinical management. Clin Ophthalmol. 2017; 11: 185-191, doi: 10.2147/OPTH.S80475, indexed in Pubmed: 28176902.

4. Bacon TH, Levin MJ, Leary JJ, et al. Herpes simplex virus resistance to acyclovir and penciclovir after two decades of antiviral therapy. Clin Microbiol Rev. 2003; 16(1): 114-128, doi: 10.1128/CMR.16.1.114-128.2003, indexed in Pubmed: 12525428.

5. Piret J, Boivin G. Resistance of herpes simplex viruses to nucleoside analogues: mechanisms, prevalence, and management. Antimicrob Agents Chemother. 2011; 55(2): 459-472, doi: 10.1128/AAC.00615-10, indexed in Pubmed: 21078929.

6. Tabbara KF, Al Balushi N. Topical ganciclovir in the treatment of acute herpetic keratitis. Clin Ophthalmol. 2010; 4: 905-912, doi: 10.2147/opth.s8666, indexed in Pubmed: 20823931.

7. Bondre VP, Sankararaman V, Andhare V, et al. Genetic characterization of human herpesvirus type 1: Full-length genome sequence of strain obtained from an encephalitis case from India. Indian J Med Res. 2016; 144(5): 750-760, doi: 10.4103/ ijmr.IJMR_747_14, indexed in Pubmed: 28361829.

8. Heming JD, Conway JF, Homa FL. Herpesvirus Capsid Assembly and DNA Packaging. Adv Anat Embryol Cell Biol. 2017; 223: 119-142, doi: 10.1007/978-3-319-53168-7_6, indexed in Pubmed: 28528442.

9. Kaye S, Choudhary A. Herpes simplex keratitis. Prog Retin Eye Res. 2006; 25(4): 355-380, doi: 10.1016/j.preteyeres.2006.05.001, indexed in Pubmed: 16807055.

10. Montgomery $\mathrm{MK}, \mathrm{Xu} \mathrm{S}$, Fire A. RNA as a target of double-stranded RNA-mediated genetic interference in Caenorhabditis elegans. Proc Natl Acad Sci U S A. 1998; 95(26): 15502-15507, doi: 10.1073/pnas.95.26.15502, indexed in $\mathrm{Pu}-$ bmed: 9860998.

11. Xu W, Jiang X, Huang L. RNA Interference Technology. Comprehensive Biotechnology. 2019: 560-575, doi: 10.1016/ b978-0-444-64046-8.00282-2.

12. Wilson RC, Doudna JA. Molecular mechanisms of RNA interference. Annu Rev Biophys. 2013; 42: 217-239, doi: 10.1146/annurev-biophys-083012-130404, indexed in $\mathrm{Pu}-$ bmed: 23654304.

13. Carmichael GG. Medicine: silencing viruses with RNA. Nature. 2002; 418(6896): 379-380, doi: 10.1038/418379a, indexed in Pubmed: 12140542.

14. Ui-Tei K, Naito Y, Takahashi F, et al. Guidelines for the selection of highly effective siRNA sequences for mammalian and 
chick RNA interference. Nucleic Acids Res. 2004; 32(3): 936-948, doi: 10.1093/nar/gkh247, indexed in Pubmed: 14769950.

15. Davison AJ. Herpesvirus systematics. Vet Microbiol. 2010; 143(1): 52-69, doi: 10.1016/j.vetmic.2010.02.014, indexed in Pubmed: 20346601.

16. Subak-Sharpe JH, Dargan DJ. HSV molecular biology: general aspects of herpes simplex virus molecular biology. Virus Genes. 1998; 16(3): 239-251, doi: 10.1023/a:1008068902673, indexed in Pubmed: 9654678.

17. Beilstein F, Cohen GH, Eisenberg RJ, et al. Dynamic organization of Herpesvirus glycoproteins on the viral envelope revealed by super-resolution microscopy. PLoS Pathog. 2019; 15(12): e1008209, doi: 10.1371/journal.ppat.1008209, indexed in Pubmed: 31790506.

18. Dubin G, Basu S, Mallory DL, et al. Characterization of domains of herpes simplex virus type 1 glycoprotein $\mathrm{E}$ involved in $\mathrm{Fc}$ binding activity for immunoglobulin $\mathrm{G}$ aggregates. J Virol. 1994; 68(4): 2478-2485, doi: 10.1128/JVI.68.4.24782485.1994, indexed in Pubmed: 7511171.

19. Weed DJ, Nicola AV. Herpes simplex virus Membrane Fusion. Adv Anat Embryol Cell Biol. 2017; 223: 29-47, doi: 10.1007/978-3-319-53168-7_2, indexed in Pubmed: 28528438.

20. Carmichael JC, Yokota $\mathrm{H}$, Craven RC, et al. The HSV-1 mechanisms of cell-to-cell spread and fusion are critically dependent on host PTP1B. PLoS Pathog. 2018; 14(5): e1007054, doi: 10.1371/journal.ppat.1007054, indexed in Pubmed: 29742155.

21. Agelidis AM, Shukla D. Cell entry mechanisms of HSV: what we have learned in recent years. Future Virol. 2015; 10(10): 1145-1154, doi: 10.2217/fvl.15.85, indexed in Pubmed: 27066105 .

22. Dingwell KS, Brunetti CR, Hendricks RL, et al. Herpes simplex virus glycoproteins $\mathrm{E}$ and I facilitate cell-to-cell spread in vivo and across junctions of cultured cells. J Virol. 1994; 68(2): 834-845, doi: 10.1128/JVI.68.2.834-845.1994, indexed in Pubmed: 8289387.

23. Brunetti CR, Dingwell KS, Wale C, et al. Herpes simplex virus $\mathrm{gD}$ and virions accumulate in endosomes by mannose 6-phosphate-dependent and -independent mechanisms. J Virol. 1998; 72(4): 3330-3339, doi: 10.1128/JVI.72.4.33303339.1998, indexed in Pubmed: 9525660.

24. Burns WH, Saral R, Santos GW, et al. Isolation and characterisation of resistant Herpes simplex virus after acyclovir therapy. Lancet. 1982; 1(8269): 421-423, doi: 10.1016/s01406736(82)91620-8, indexed in Pubmed: 6121091.

25. Crumpacker CS, Schnipper LE, Marlowe SI, et al. Resistance to antiviral drugs of herpes simplex virus isolated from a patient treated with acyclovir. N Engl J Med. 1982; 306(6): 343-346, doi: 10.1056/NEJM198202113060606, indexed in Pubmed: 6275267.

26. Farnsworth A, Goldsmith K, Johnson DC. Herpes simplex virus glycoproteins $\mathrm{gD}$ and $\mathrm{gE} / \mathrm{gI}$ serve essential but redundant functions during acquisition of the virion envelope in the cytoplasm. J Virol. 2003; 77(15): 8481-8494, doi: 10.1128/ jvi.77.15.8481-8494.2003, indexed in Pubmed: 12857917.

27. McMillan TN, Johnson DC. Cytoplasmic domain of herpes simplex virus $\mathrm{gE}$ causes accumulation in the trans-Golgi network, a site of virus envelopment and sorting of virions to cell junctions. J Virol. 2001; 75(4): 1928-1940, doi: 10.1128/ JVI.75.4.1928-1940.2001, indexed in Pubmed: 11160692.

28. Turner A, Bruun B, Minson T, et al. Glycoproteins gB, gD, and $\mathrm{gHgL}$ of herpes simplex virus type 1 are necessary and sufficient to mediate membrane fusion in a Cos cell trans- fection system. J Virol. 1998; 72(1): 873-875, doi: 10.1128/ JVI.72.1.873-875.1998, indexed in Pubmed: 9420303.

29. Zhe R, Mei-Ying Z, Kitazato K, et al. Effect of siRNA on HSV-1 plaque formation and relative expression levels of UL39 mRNA. Arch Virol. 2008; 153(7): 1401-1406, doi: 10.1007/s00705-008-0110-1, indexed in Pubmed: 18551244.

30. Bhuyan PK, Karik K, Capodici J, et al. Short interfering RNA-mediated inhibition of herpes simplex virus type 1 gene expression and function during infection of human keratinocytes. J Virol. 2004; 78(19): 10276-10281, doi: 10.1128/ JVI.78.19.10276-10281.2004, indexed in Pubmed: 15367593.

31. Norberg P, Bergström T, Rekabdar E, et al. Phylogenetic analysis of clinical herpes simplex virus type 1 isolates identified three genetic groups and recombinant viruses. J Virol. 2004; 78(19): 10755-10764, doi: 10.1128/JVI.78.19.1075510764.2004, indexed in Pubmed: 15367642.

32. Stingley SW, Ramirez JJ, Aguilar SA, et al. Global analysis of herpes simplex virus type 1 transcription using an oligonucleotide-based DNA microarray. J Virol. 2000; 74(21): 9916-9927, doi: 10.1128/jvi.74.21.9916-9927.2000, indexed in Pubmed: 11024119.

33. Duffy S, Shackelton LA, Holmes EC. Rates of evolutionary change in viruses: patterns and determinants. Nat Rev Genet. 2008; 9(4): 267-276, doi: 10.1038/nrg2323, indexed in Pubmed: 18319742.

34. Sarisky RT, Nguyen TT, Duffy KE, et al. Difference in incidence of spontaneous mutations between Herpes simplex virus types 1 and 2. Antimicrob Agents Chemother. 2000; 44(6): 1524-1529, doi: 10.1128/AAC.44.6.1524-1529.2000, indexed in Pubmed: 10817703.

35. Coen DM, Furman PA, Gelep PT, et al. Mutations in the herpes simplex virus DNA polymerase gene can confer resistance to 9-beta-D-arabinofuranosyladenine. J Virol. 1982; 41(3): 909-918, doi: 10.1128/JVI.41.3.909-918.1982, indexed in Pubmed: 6284981.

36. Kamp C, Wilke C, Adami C, et al. Viral evolution under the pressure of an adaptive immune system: Optimal mutation rates for viral escape. Complexity. 2003; 8(2):28-33, doi: 10.1002/cplx.10067.

37. Gitlin L, Stone JK, Andino R. Poliovirus escape from RNA interference: short interfering RNA-target recognition and implications for therapeutic approaches. J Virol. 2005; 79(2): 1027-1035, doi: 10.1128/JVI.79.2.1027-1035.2005, indexed in Pubmed: 15613331.

38. Kahana R, Kuznetzova L, Rogel A, et al. Inhibition of footand-mouth disease virus replication by small interfering RNA. J Gen Virol. 2004; 85(Pt 11): 3213-3217, doi: 10.1099/ vir.0.80133-0, indexed in Pubmed: 15483234.

39. Jin F, Li S, Zheng K, et al. Silencing herpes simplex virus type 1 capsid protein encoding genes by siRNA: a promising antiviral therapeutic approach. PLoS One. 2014; 9(5): e96623, doi: 10.1371/journal.pone.0096623, indexed in Pubmed: 24794394.

40. Chen W, Yan W, Du Q, et al. RNA interference targeting VP1 inhibits foot-and-mouth disease virus replication in BHK-21 cells and suckling mice. J Virol. 2004; 78(13): 6900-6907, doi: 10.1128/ JVI.78.13.6900-6907.2004, indexed in Pubmed: 15194766.

41. Watanabe T, Umehara T, Kohara M. Therapeutic application of RNA interference for hepatitis C virus. Adv Drug Deliv Rev. 2007; 59(12): 1263-1276, doi: 10.1016/j.addr.2007.03.022, indexed in Pubmed: 17822803.

42. Coburn GA, Cullen BR. Potent and specific inhibition of human immunodeficiency virus type 1 replication by RNA interference. J Virol. 2002; 76(18): 9225-9231, doi: 10.1128/ jvi.76.18.9225-9231.2002, indexed in Pubmed: 12186906. 